\title{
InVESTIGATING THE High-DENSITY COMPRESSION OF BULK WOOL
}

\author{
T. J. Gale, J. P Tyndale-Biscoe, G. A. Moore
}

\begin{abstract}
The physical properties of bulk wool compressed to high density are largely unknown. Improved knowledge may assist in prediction of variables such as force and displacement during compression. An experimental multi-axial press was developed to allow investigation of these properties for application to the wool dumping industry. The press had a 170 tonne main axial ram, a multi-axial moveable-wall pressing chamber of 150 tonne capacity, instrumentation to measure wall forces and displacements, and a PC/PLC-based control system. Tests were done to investigate wool's pressing characteristics, including pressure-density relationships and chamber wall forces. Wool's compression characteristics were found to be highly nonlinear. Lubrication was found to significantly reduce wall friction forces. A tensile failure occurred in the wool during a test when the side-platens were free to move. The results may find application in the design of high-capacity wool dumping presses.
\end{abstract}

Keywords. Dumping, Forces, Friction, Pressing, Triaxial, Wool.

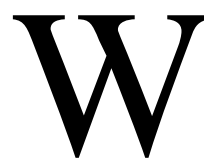
ool dumping (pressing wool bales to form high-density modules) is well established both in Australia and worldwide. Wool bales are dumped to reduce their volume and thereby minimize export costs. Large presses are used, and the press operation may be uniaxial, biaxial, or triaxial.

Despite significant investment in the industry, there is a lack of authoritative information on the pressing characteristics of wool. This may be attributed, partly, to a lack of suitable facilities for performing comprehensive experimental investigations. Improved knowledge of wool's pressing characteristics would lead to better prediction of forces and displacements during compression and assist with press design.

There are a number of factors that complicate wool dumping. Pressing may be uniaxial, biaxial, or triaxial. The nonlinear nature of wool at high density means that these three pressing modes are independent. If a model of wool compression is to be developed, then these three modes of compression can only be described using separate models.

There are a large number of characteristics of wool that may affect its pressing behavior. These include: the mass of wool fiber present; the physical condition of the staples, including the raw staple density (Gale and Moore, 1990); the structural properties of the fibers, including the elastic modulus in bending, compression, and tension and the secondary effects of the fiber diameter (Van Wyk, 1946); the

Article was submitted for review in November 2004; approved for publication by the Power \& Machinery Division of ASAE in February 2005.

The authors are Timothy J. Gale, Lecturer, School of Engineering, University of Tasmania, Hobart, Tasmania, Australia; J. Paul Tyndale-Biscoe, Research Engineer, and Graham A. Moore, Senior Lecturer, Department of Civil and Environmental Engineering, University of Melbourne, Victoria, Australia. Corresponding author: Timothy J. Gale, GPO Box 252-65, Hobart, Tasmania, 7001, Australia; phone: +61-3-62262753; fax: +61-3-62267247; e-mail: t.gale@utas.edu.au. moisture content of the specimen; the flow of grease between the wool fibers and the temperature of the specimen (for greasy wool) (Walls, 1988a, 1988b); vegetable matter and other contamination; and the effects of fiber crimp.

Previous investigations into wool dumping have not been entirely satisfactory. Van Wyk's (1946) theoretical model of wool compression, involving a parabolic relationship between pressure and volume for wool, was based on the assumption that the compression of the mass consisted only of the bending of fibers. The model was of limited practical use at high density because of various simplifying assumptions that were made, including neglecting possible twisting, slippage, and extension of the fibers and frictional forces, the volume of the material and boundary effects, and that the model required fibers to be randomly orientated.

Numerous workers have investigated wool compression using instrumented presses, but none of this work was entirely suitable in regard to similarity of experimental procedures to commercial wool dumping. The aim was generally to find useful empirical relationships for stresses on platen surfaces, densities achieved, and dimensions of dumped bales. WRONZ (1972) and Burrow (1983), for example, investigated forces on the surface of press chambers using a biaxial and a triaxial commercial industrial press, respectively. The work was of restricted application due to the specific nature of the presses and testing programs. In particular, only two or three types of wool were used in the investigations, homogeneity of the wool was not ensured, repetitions of experiments were not performed, and the press configurations were invariant. Reasons for the limitations included the large quantity of wool (up to $600 \mathrm{~kg}$ ) that was required for each test to ensure the normal operation of the presses, and the commercial nature, physical size, and complexity of the operations. Other workers using full-size presses include Lhuede (1968) and Volchenock and Doktorov (1972).

Smaller scale laboratory equipment has also been used. For example, David and Downs (1968) constructed and used 

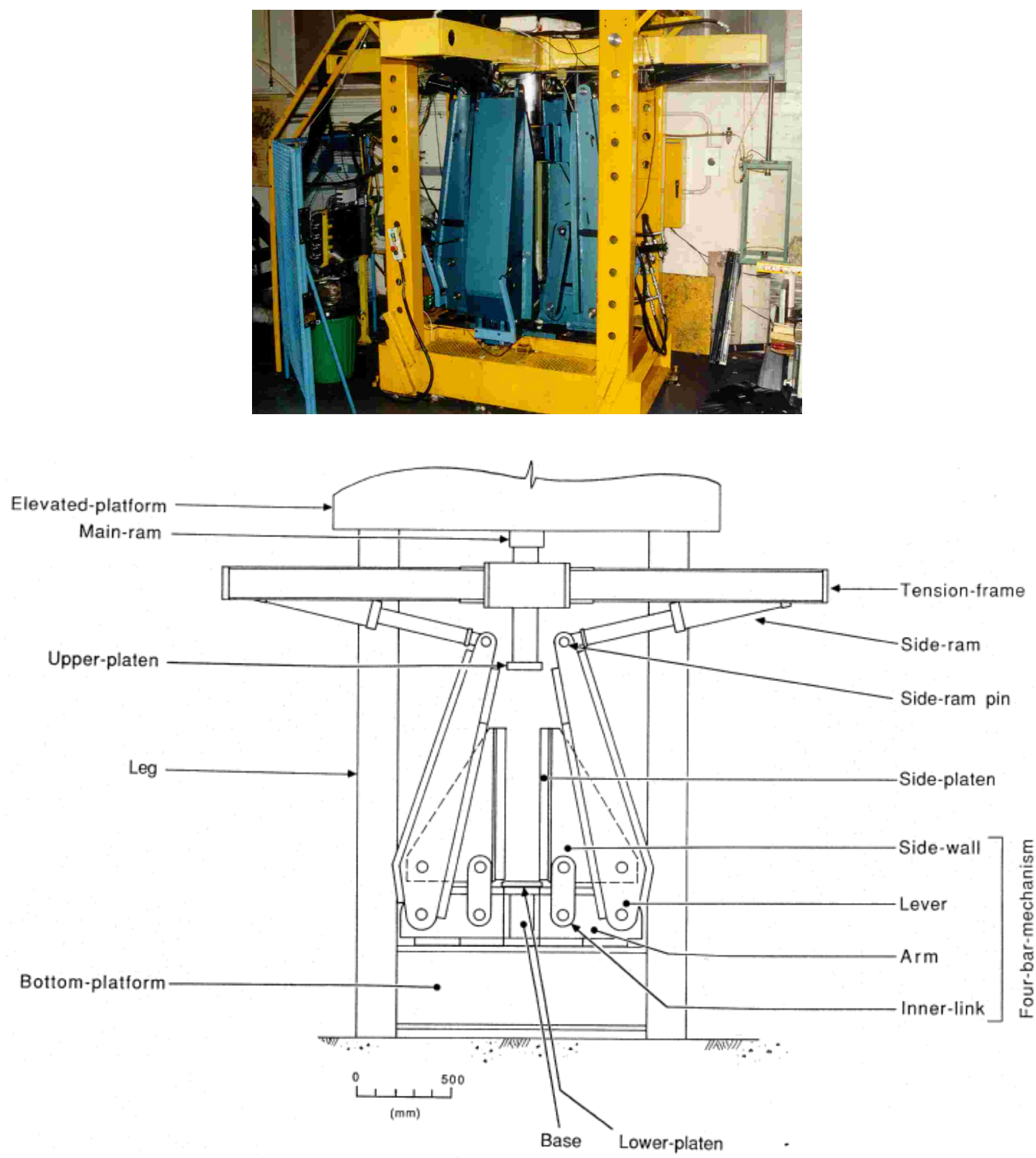

Figure 1. Experimental high-density wool press.

an experimental biaxial press. Two mutually perpendicular surfaces of the pressing chamber were driven by hydraulic rams and were capable of applying thrusts of 50 tons and 20 tons in the longitudinal and lateral directions, respectively. Scale-model bales with masses ranging from 4.4 to $21.5 \mathrm{~kg}$ were pressed, the heavier bales (for example) typically being pressed from about $600 \mathrm{~mm}$ to $370 \mathrm{~mm}$ (longitudinal dimension) and from $400 \times 400 \mathrm{~mm}$ to $400 \times$ $200 \mathrm{~mm}$ (lateral dimension). This press had no facility for triaxial pressing, and the biaxial component of pressing was done from only one side of the bale.

Walls (1988a, 1988b) described two experimental biaxial presses used to press a range of wools. The presses had the facility to heat the wool prior to pressing, which resulted in a substantial reduction in the pressing forces. However, the presses were relatively small (only up to $2 \mathrm{~kg}$ maximum sample mass) and, due to the wool loading arrangements, were only suitable for performing tests with a large biaxial component. Other workers utilizing experimental presses include Lheude (1968) and Thompson and Whiteley (1985).

Numerical modeling is an alternative approach that has not been well explored for this application. An initial investigation was done by Guruparan et al. (1990); however, they were not successful at predicting wool's compression characteristics because of insufficient knowledge of the model parameters, including Young's modulus, Poisson's ratio, and the coefficient of friction. For high-density wool, these parameters are highly nonlinear and are functions of the wool's density and compression history. Guruparan's work cannot be applied until adequate values are found for these parameters.

The size of the press chamber is also a significant factor in regard to the practicality of the press and the validity of the experimental results. An investigation was performed by 
Moore et al. (1988), consisting of uniaxial pressing of wool in a series of geometrically similar cylindrical chambers ranging from $75 \mathrm{~mm}$ to $300 \mathrm{~mm}$ diameter, to find pressuredensity relationships. The platen pressure to achieve a specified density was found as a function of chamber diameter. A significant increase in pressure was observed if the chamber diameter was less that about $150 \mathrm{~mm}$. The conclusion was that small chambers could not be used to represent the behavior of wool in a full-size chamber (width approximately 600 to $700 \mathrm{~mm}$ ), and that a press with a scale of 1:4 (linear dimensions, relative to commercial presses) was the smallest that would give results that could be reliably extrapolated to full size. This supported the work of David and Downs (1968), who found that biaxially pressing $1 / 3$-scale bales (minimum lateral dimensions of approximately $120 \times 235 \mathrm{~mm}$ in the press after pressing) gave good agreement with results obtained from pressing full-size bales. The reason why the chamber width was a critical dimension appears to relate to the greater proportion of wall area in smaller presses (leading to a higher proportion of wall friction).

A single full-scale industrial experiment requires up to $650 \mathrm{~kg}$ of wool, with pressing from 300 to $1200 \mathrm{~kg} \mathrm{~m}^{-3}$ and applied loads up to $20 \mathrm{MPa}$. Unfortunately, such experiments are often impractical because the large quantity of wool required makes it difficult to maintain homogeneity between experiments. In addition, it is difficult or impossible to change press configurations, experiments take excessive time, and the presses are generally too expensive to be used exclusively for research.

We describe here an experimental press suitable for investigating the high-density compression of bulk wool, and the results of initial experimental investigations using the press. The press was relatively large and enabled investigations involving high stress, large strains, and uniaxial, biaxial, and triaxial pressing. A brief discussion relating to this press may also be found in Tyndale-Biscoe et al. (1990).

\section{MeTHOD}

\section{Development of the Experimental Press}

The experimental press (fig. 1) had six rigid platens, five of which were moveable. The four large moving platens were called the side-platens, the small moving platen was the upper-platen, and the small fixed platen was the lower-platen. The platen arrangement formed a cuboidal cavity called the chamber, and in this was placed the specimen.

The chamber had nominal maximum dimensions of $800 \mathrm{~mm}$ between the upper- and lower-platens, and $200 \mathrm{~mm}$ between opposing side-platens, i.e., $800 \times 200 \times 200 \mathrm{~mm}$. The smallest chamber size achievable was $125 \times 133 \times$ $133 \mathrm{~mm}$. The chamber width was designed specifically to be the minimum size that would allow results to be applied to the wool dumping process. This minimized the forces on the chamber, resulting in a cheaper and simpler design, and minimized the mass of wool required for each test, thereby minimizing the number of wool bales required for a series of tests and thus improving the homogeneity of the wool samples. It also allowed easier blending to improve homogeneity and minimized the time required to prepare wool and perform tests.
The apparatus could apply high surface pressure to the specimen. The maximum pressure achieved depended on the specimen's initial dimensions, density, and deformation characteristics and was ultimately limited by the strength of the side-wall supporting structure. However, forces of $1700 \mathrm{kN}$ and $1500 \mathrm{kN}$ could be applied through the upper-platen and each side-platen, respectively, and stresses of $20 \mathrm{MPa}$ could be applied to specimens in the chamber without risk of overloading the structure.

The platens were mild steel with ground machined surfaces. In some experiments, a lubricant was also applied. The lubricant was an experimental mixture of soap and water, which was smeared over the platen surface to lower the surface friction (fig. 2). A barrier was used to separate the lubricant from the wool. This consisted of a thin film of plastic (i.e., domestic plastic food wrap, "Glad Wrap" in this case).

Each of the upper- and lower-platens also had a $33 \mathrm{~mm}$ long steel spike (19 $\mathrm{mm}$ diameter at the base, tapering to $1 \mathrm{~mm}$ diameter at the tip) protruding from its center. The spikes prevented the upper and lower ends of specimens from slipping on the platens, which they were inclined to do, especially with unsupported uniaxial loading (loading without support from the side-platens). The spikes were located in the center of each platen so as not to inhibit radial expansion of the ends of specimens.

Each side-platen was supported by a four-bar mechanism comprising the supporting base, an inner-link, a lever, and a side-wall (fig. 1). These mechanisms drove the side-walls, to which were bolted the side-platens. The side-platens were used to load the specimen in the lateral direction. The loading was applied by the levers, which controlled either the position or force on each side-platen. The levers were driven by hydraulic rams (i.e., the side-rams), which reacted against the tension-frame. The simplicity of the four-bar mechanisms allowed forces acting on the side-platens to be determined.

\section{Upward Rotation of the Side-Platens}

Two of the side-walls (on opposing sides of the chamber) were constructed to rotate upwards to provide access to the chamber using a unique system newly developed for this

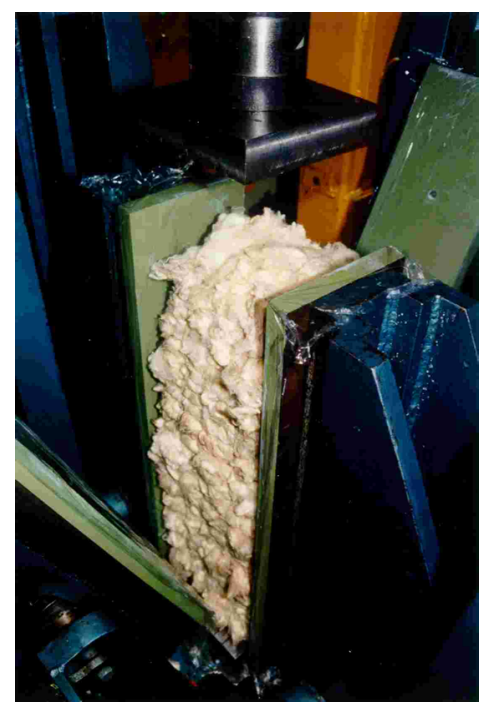

Figure 2. Wool in lubricated, retracted chamber (before pressing). 
project. When the side-walls rotated, they moved inside recesses within the levers. The rotation was achieved by extending specially designed inner-links on two of the four-bar mechanisms, by retracting a small hydraulic retraction-ram that operated a reverse-toggle mechanism that formed part of the links. The rotation mechanisms locked into position during normal pressing operations, with the mechanism on the centerline of the linkage, ensuring that the linkage was rigid both in tension and compression. The mechanism did not use an over-center locking technique, which would not have worked in this case, because the load in the linkage may either be in tension or compression during wool compression.

The linkage locking arrangement is detailed in figure 3 . The locking was achieved automatically by means of the locking-plate when the retraction-ram was extended. When locked, the locking-plate also ensured that there was no rotation of the locking arrangement about pin $\mathrm{C}$, and this ensured that the retraction-ram also became an additional link in the four-bar mechanism. Furthermore, the retractionram was parallel to, and of the same length as, the upper and lower links in the four-bar mechanism. Therefore, the retraction-ram moved with the four-bar linkage and kept the locking arrangement locked throughout the working range of side-platen movement. When the retraction-ram was retracted, the locking-plate came away from the links, and the locking arrangement was free to rotate about pin $\mathrm{C}$.

The rotation mechanism was compact, being mainly housed within the two side-walls, but it had the same load carrying capacity as the plain links on the other sides. Pin B on each mechanism passed completely through the sidewalls (fig. 3), and relative movement was accommodated by a large, irregularly shaped hole made in the side-walls through which the pin passed.

\section{Instrumentation}

Instrumentation allowed measurement of displacement and force on each of the six walls. Transducers included ten load cells and five potentiometers, which were used to measure the forces on the platens and the displacements of the platens, respectively. The upper-platen, lower-platen, side-ram, and inner-link load cells were all custom-made. The upper-platen, side-platen, and side-ram load cells sensed the normal force on each platen. The inner-link load cells
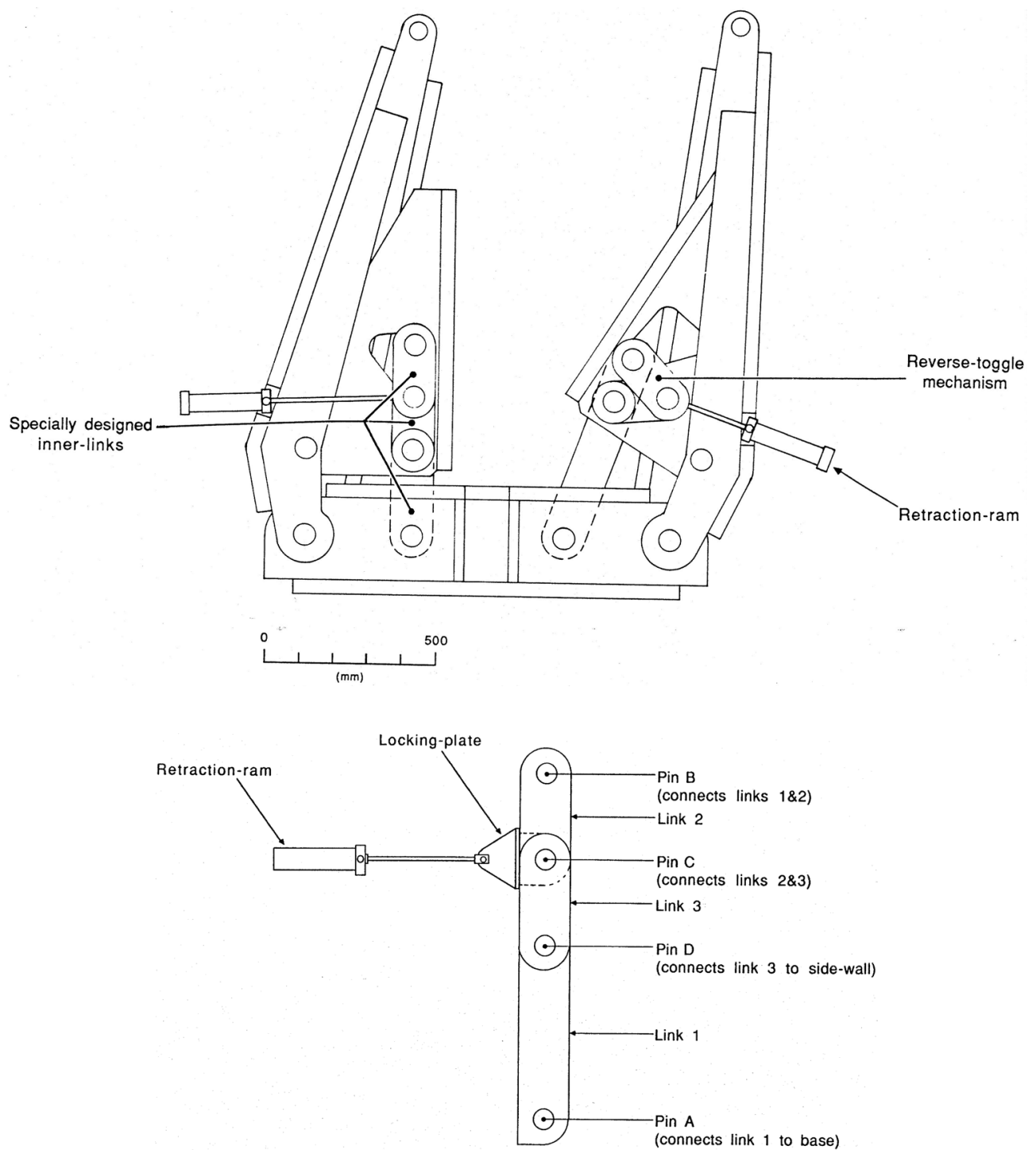

Figure 3. Unique retracting wall arrangement and detail of locking inner-links. 
sensed the force on each pair of inner-links. The difference between the forces sensed by the upper- and lower-platens was used to calculate the (average) shear forces on the side-platens. The forces sensed by the inner-link load cells were used to calculate the centroid of the normal force on the side-platens. The upper- and lower-platen load cells were cylindrical column load cells supporting the platens. The pins connecting the side-rams to the levers were instrumented with strain gauges to form the side-ram load cells. The inner-links of the four-bar mechanisms were instrumented with strain gauges to form the inner-link load cells.

The potentiometers included one ten-turn potentiometer (the upper-platen displacement transducer) and four linear potentiometers (the side-platen displacement transducers). The upper-platen displacement transducer was driven by a chain and cog arrangement. The chain was connected via a cable and turning blocks to the main-ram, and was tensioned by a mass that was suspended from the other end of the chain. The side-platen displacement transducers were connected between the levers and rigid brackets bolted to the press base.

\section{Press Control}

The press was automatically controlled by using a PC interfaced to a programmable logic controller (PLC). A manual control system could also be used instead of the computer. The computer also performed 12-bit data acquisition of the press forces and displacements using a DT2801 board (Data Translation, Inc., Marlboro, Mass.). The measurements made by the computer were used in a feedback loop to control either the force or the displacement of the platens during pressing. Using this capability, the stress (or strain) on each platen could be controlled.

\section{Loading Wool into the Chamber}

The wool was loaded into the press chamber in the same way as in the wool pressing industry, that is, initial charging from the top (longitudinal direction), the same as when loading wool into a farm bale prior to a high-density compression operation. The wool had a low density (about $60 \mathrm{~kg} \mathrm{~m}^{-3}$ ) in its free state and needed to be forced into the chamber. This was done by individually forcing small portions, or charges, into the chamber until the desired initial density was achieved. Because the specimens were elastic to some degree, a force of approximately $1 \mathrm{kN}$ was required to push each charge into the chamber and to then restrain it until the next charge was loaded. This was done by using the upper-platen to force each charge into the chamber, and using the piston rods $(12.7 \mathrm{~mm}$ diameter $)$ from two small pneumatic rams ( $40 \mathrm{~mm}$ bore diameter) to restrain the charge until the next charge was loaded. When extended, these piston rods extended $60 \mathrm{~mm}$ into the chamber from opposite sides. The piston rods passed through $15 \mathrm{~mm}$ diameter holes in the side-platens and emerged $600 \mathrm{~mm}$ above the base-platen.

When using lubricated platens, each specimen was usually loaded into the chamber before the lubrication was applied. The chamber was then partially opened, and the specimen was restrained with string. Special upper-and lower-platens, with grooves, were used at this stage to allow the string to pass around the specimen. The chamber was then fully opened, and the specimen was removed from the chamber. The plain upper- and lower-platens were then fitted, and lubrication was applied to all the platens. The specimen was then inserted again into the chamber, and the chamber was closed to its initial position.

\section{EXPERIMENTAL Method}

Three experiments were performed to demonstrate the characteristics of wool during high-density pressing. Each experiment comprised a single compression test using 21 micron diameter greasy wool from a $200 \mathrm{~kg}$ bale. Initial wool preparation consisted of manual blending (fig. 4) using all the wool from the bale until a homogenous mix was achieved, as determined visually. Specimens were then taken from this homogenous mix and loaded into the chamber. The mass of wool used in each test was determined by the desired initial wool density and the initial dimensions of the chamber, which were chosen to be comparable to typical commercial practice.

The first experiment was uniaxial compression using plain platens, a $200 \times 200 \mathrm{~mm}$ chamber cross-section, and a $9.6 \mathrm{~kg}$ specimen. Wool was pressed from an initial density of $300 \mathrm{~kg}$ $\mathrm{m}^{-3}$ to a final in-press density of $1200 \mathrm{~kg} \mathrm{~m}^{-3}$. The second experiment was identical to the first except the platens were lubricated. The third experiment was the same as the first except the side-platens were free to move outwards and only $7.2 \mathrm{~kg}$ of wool was used (the reduced mass reduced the length of the unsupported column, resulting in improved stability under high load).

The normal stress on the platens was termed the platen pressure and was evaluated by dividing the total force exerted normal on the platen surface by the surface area of the platen in contact with the specimen. The shear stress on the side-platens was termed the wall shear and was evaluated by dividing the tangential force on the platen surface by the surface area of the platen in contact with the specimen. The coefficient of friction of the wool sliding on the surface of the side-platens was evaluated by dividing the wall shear by the platen pressure. The height of the centroid of the platen pressure above the lower-platen was calculated by using the sum of moments on the side-walls with known values for the platen pressure and wall shear.

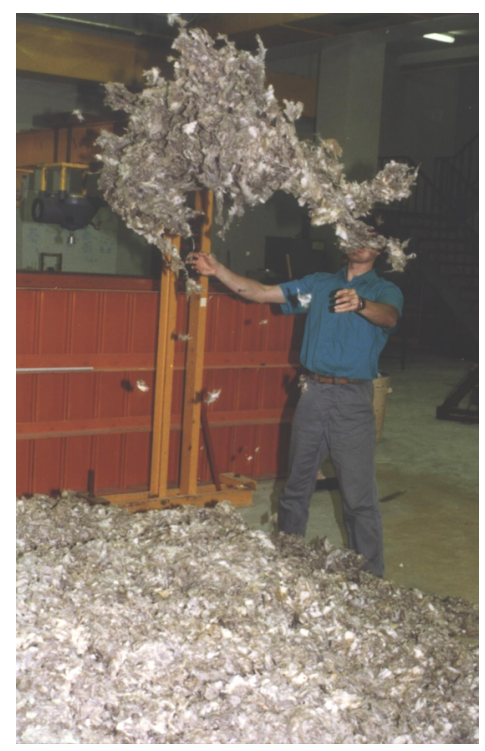

Figure 4. Manual blending of the wool to achieve a homogenous mix. 


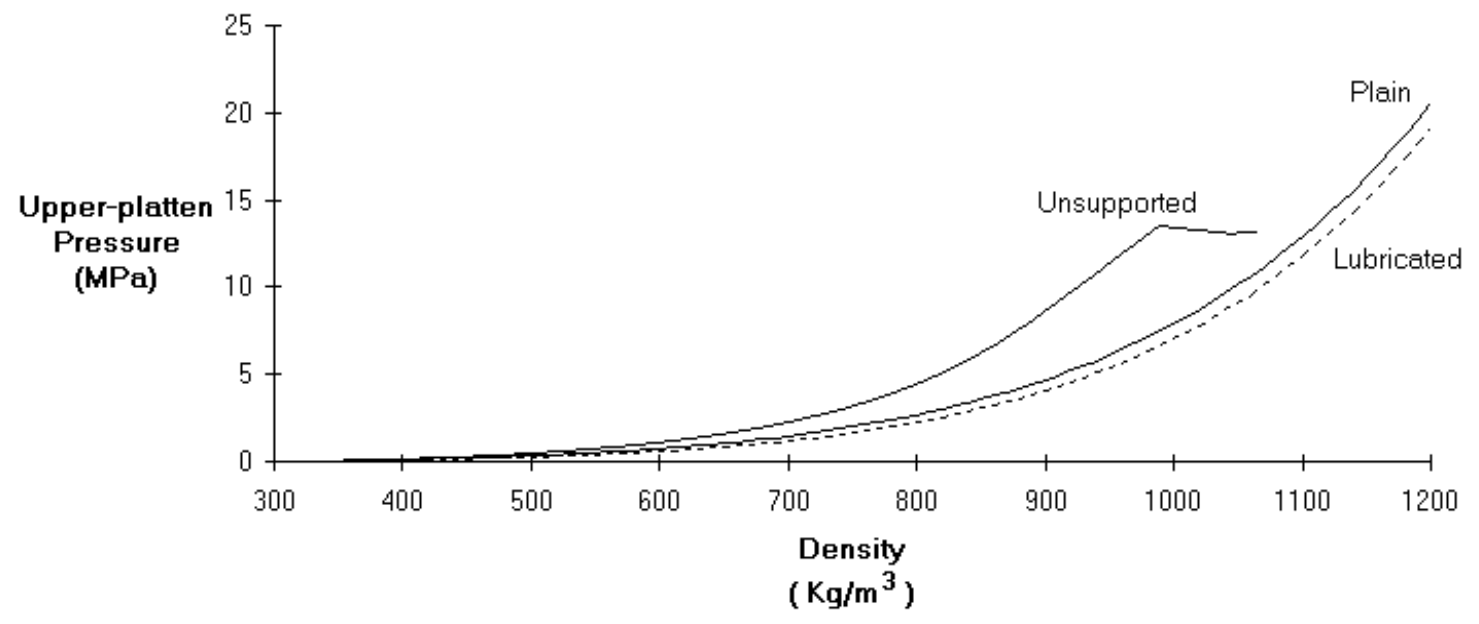

Figure 5. Upper-platen pressure as a function of density for compression tests with three different chamber side-platen configurations (plain, lubricated, and no side-platens). There was a tensile failure in the wool for the unsupported column (no side-platens).
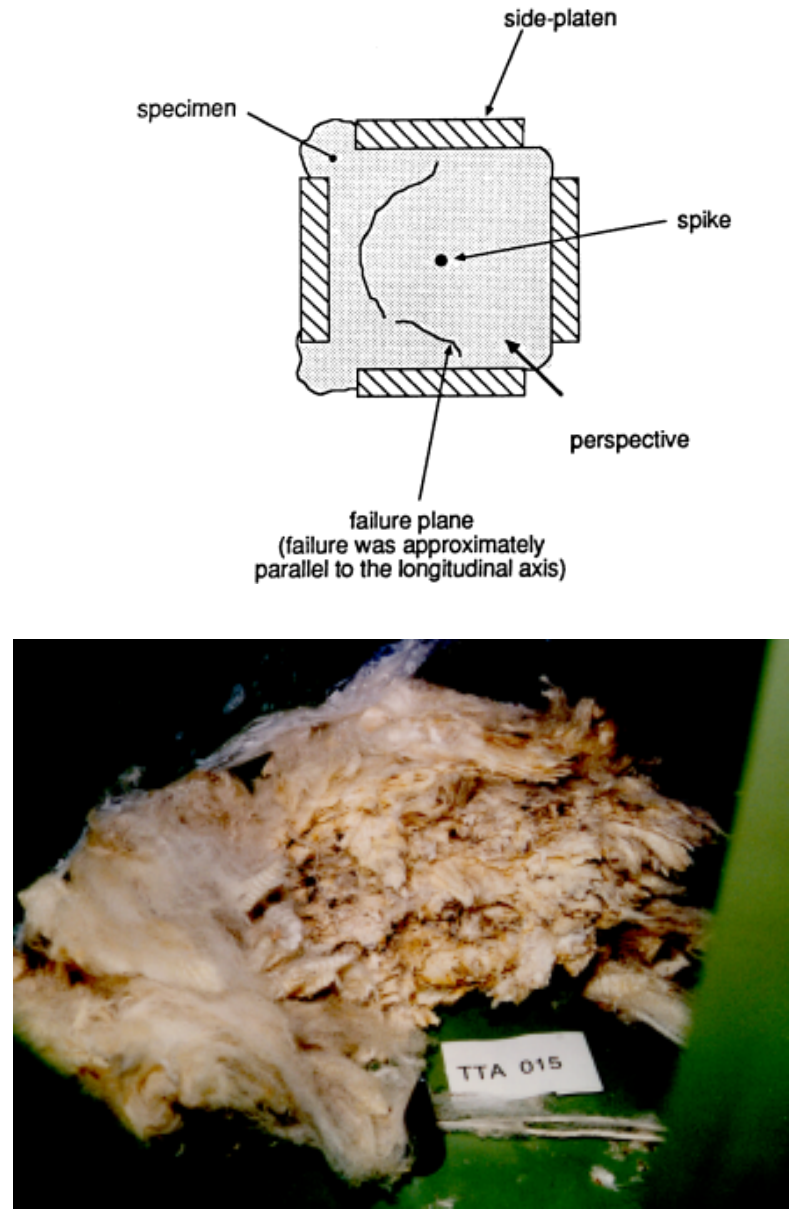

Figure 6. Schematic and photograph of the tensile failure in the unsupported wool column.

\section{RESULTS}

Results were arranged as functions of either wool density or upper-platen pressure (UPP). UPP is shown as a function of density in figure 5 for each of the three tests (plain, lubricated, and no side-platens). A tensile failure occurred in the wool in the unsupported specimen. The failure was a sudden event and occurred at a density of $990 \mathrm{~kg} \mathrm{~m}^{-3}$, i.e., the point of maximum pressure on the "unsupported" curve in (fig. 5). A schematic and a photograph of the failure are shown in figure 6 .

The remaining results, for specimens supported with plain and lubricated side-platens (constant cross-section chamber), were plotted against UPP. These were side-platen pressure as a percentage of UPP (fig. 7), lower-platen pressure as a percentage of UPP (fig. 8), wall shear stress as a percentage of UPP (fig. 9), the coefficient of friction of wool on the side-platens (fig. 10), and the height of the centroid of side-platen pressure (fig. 11).

\section{DisCUSSION}

The experimental press allowed useful experiments to be done in a timely fashion. It allowed individual tests to be done using less than $10 \mathrm{~kg}$ of wool, which was important in order to allow preparation of a homogenous mix of wool, minimizing variation in specimen properties between tests.

Comparing UPP for the three main tests, it was observed that UPP increased exponentially as a function of wool density, being lowest for lubricated platens, followed by plain platens and then the unsupported column. At a density of $1200 \mathrm{~kg} \mathrm{~m}^{-3}$, lubrication lowered the UPP by approximately $7.5 \%$. A relatively low density was achieved when pressing wool as an unsupported column. This was due to lateral bulging of the specimen, which occurred because the specimen was stressed longitudinally but not laterally.

The observed tensile failure of wool in the third test is an interesting and previously unreported phenomenon. The sudden failure resulted in lack of structural integrity in the specimen and had serious implications for the press. The fractured wool was free to move outwards, providing no support for the wool on top, which was liable to move into this vacated area. This led to the upper-platen being forced to this side, with the danger of buckling of the ram. Voids and bulging of the specimen after failure resulted in an apparent increase in density after tensile failure.

Other results are also of interest. The side-platen pressure ratio increased from a value of zero to around $40 \%$ to $50 \%$ of the UPP at a UPP value of $1 \mathrm{MPa}$, from which point it increased steadily. The side-platen pressure ratio was 


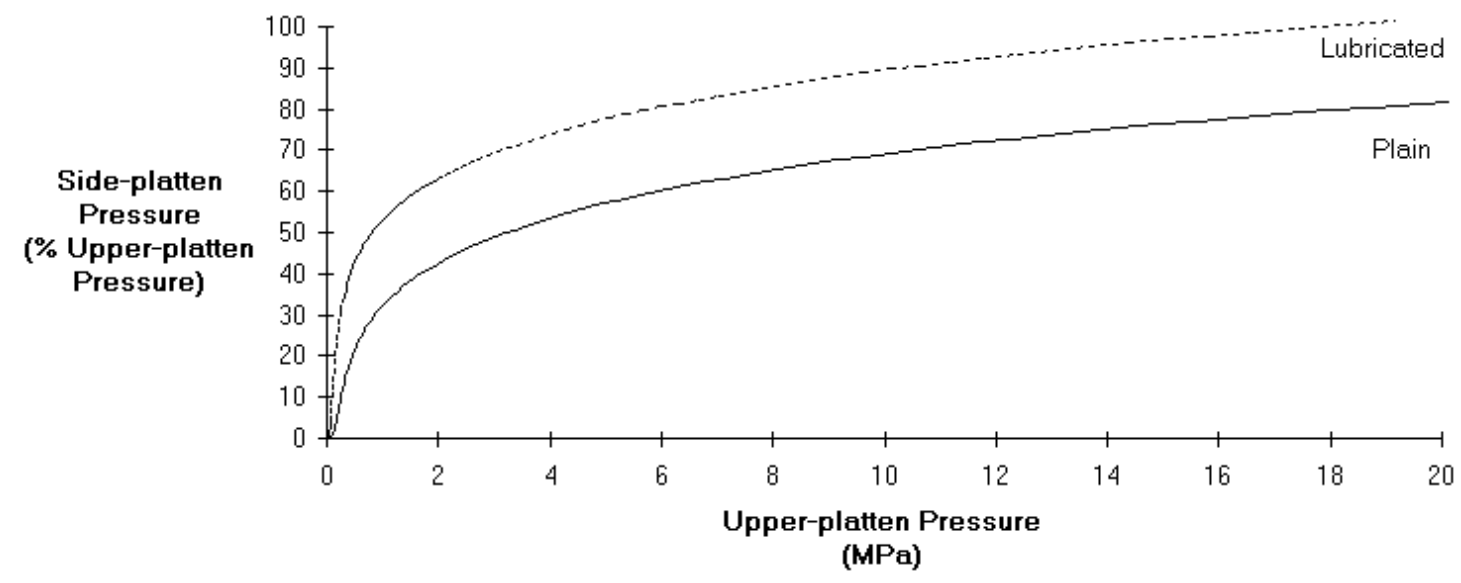

Figure 7. Side-platen pressure as a percentage of UPP.

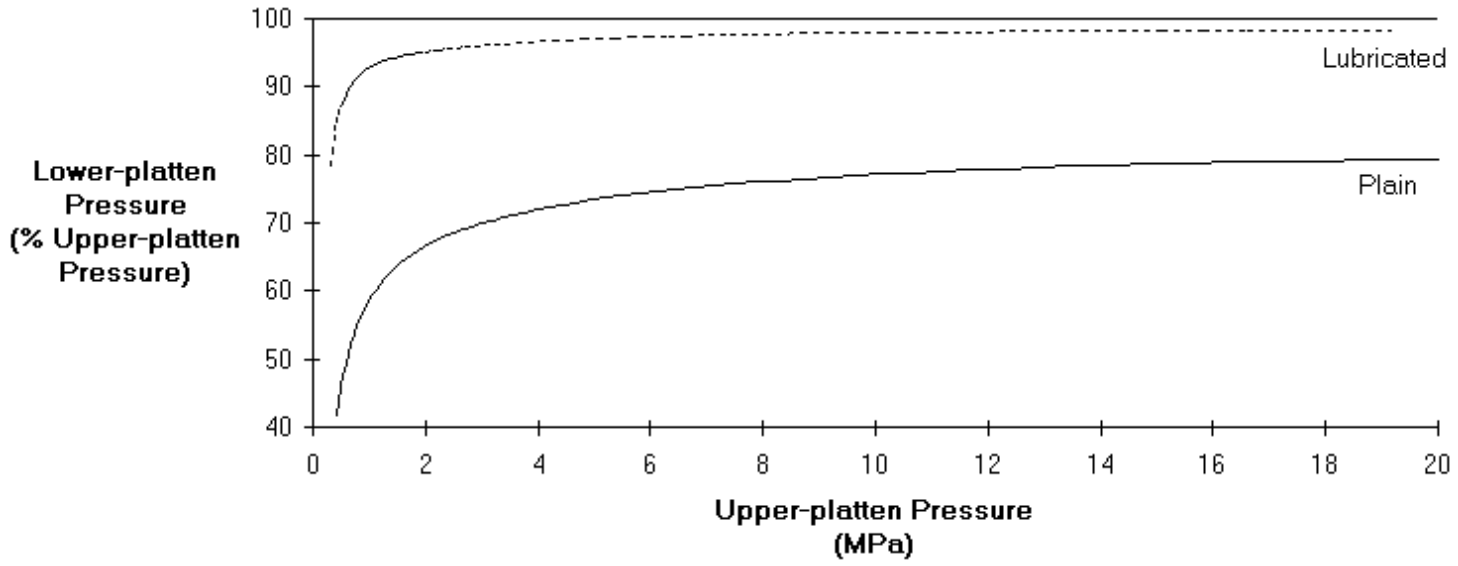

Figure 8. Lower-platen pressure as a percentage of UPP.

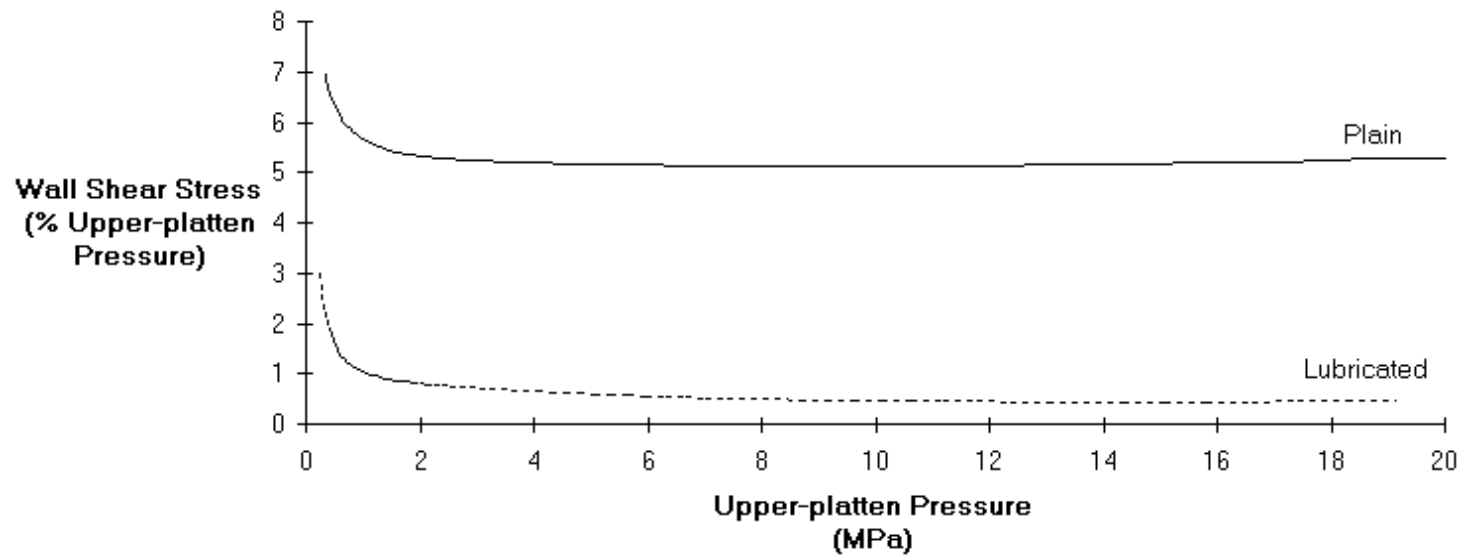

Figure 9. Wall shear stress as a percentage of UPP.

significantly higher with lubricated platens, due to the average pressure in the specimen being higher than with plain platens. At the end of the test, the side-platen pressure on the lubricated platens was $102 \%$ of the UPP and appeared to be increasing further. The explanation for how the side-platen pressure exceeded the applied UPP is not known, although a possible explanation is that the structural properties of the bulk wool resulted in a "lever effect" as it was compressed.

The lower-platen pressure ratio indicated the percentage of the UPP that was transferred through the specimen to the chamber base. Pressure loss between the upper- and lowerplatens was due to longitudinal frictional resistance between the specimen and the side-platens. Initially, the LPP was a very small percentage of the UPP, but it rose significantly for UPP pressures above $1 \mathrm{MPa}$, eventually reaching around $80 \%$ and $98 \%$ of UPP for plain and lubricated platens, respectively, at a UPP of $20 \mathrm{MPa}$.

The wall shear stress, generated by the longitudinal friction forces on the side-platens, initially had relatively high values, but at UPP stresses above $1 \mathrm{MPa}$ it was reduced 


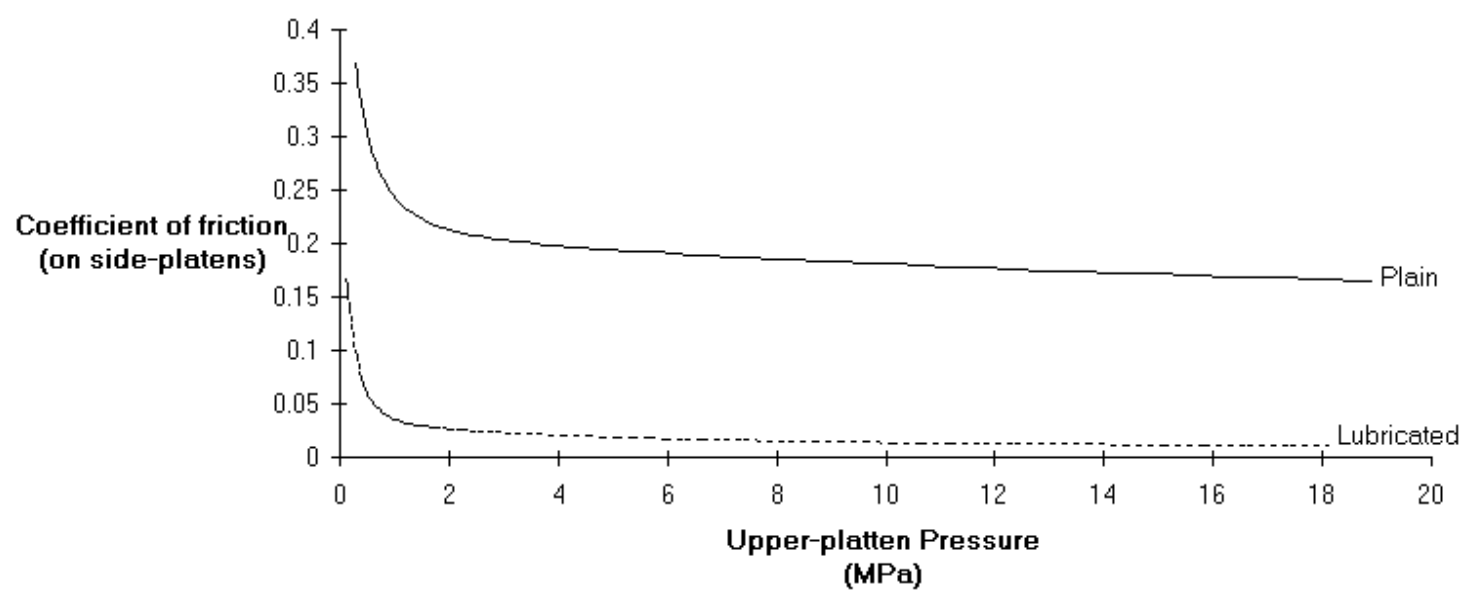

Figure 10. The coefficient of friction of wool on the side-platens.

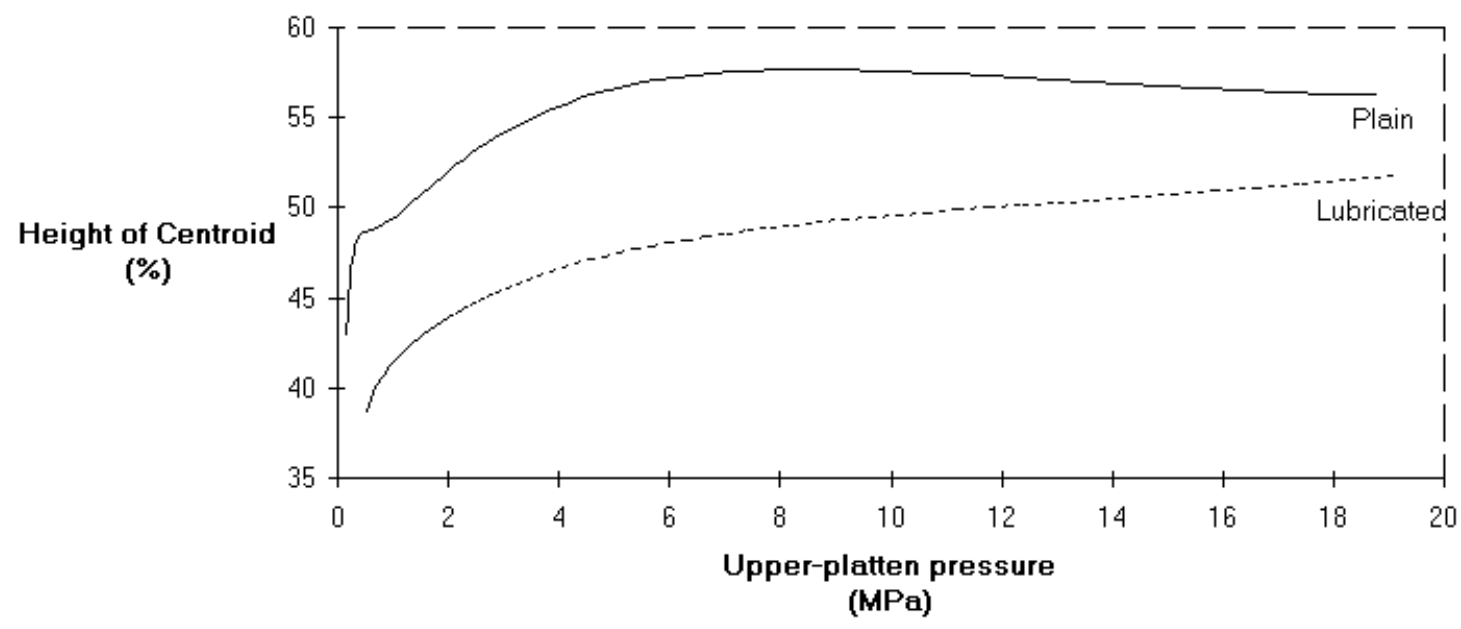

Figure 11. Height of the centroid of the side-platen pressure.

to approximately $5 \%$ and $0.5 \%$ of UPP for plain and lubricated platens, respectively.

The measured average coefficient of friction of the specimen on the side-platens was also found to be a function of UPP. Results were similar to those for wall shear stress, with final values of approximately 0.16 and 0.011 for plain and lubricated platens, respectively, at a UPP of $20 \mathrm{MPa}$.

The centroid of the side-platen pressure was also a function of UPP, starting low on the wall (near the base) and rising significantly for UPP above $1 \mathrm{MPa}$. The centroid was lower for lubricated platens, although it rose consistently with UPP to a value of $52 \%$ at a UPP of $20 \mathrm{MPa}$. With plain platens, the centroid reached a maximum value of $58 \%$ at a UPP of $9 \mathrm{MPa}$ and remained relatively constant with increasing UPP. The centroid was unexpectedly low on the lubricated platens for low values of stress. There may possibly be a greater tendency for lateral expansion in the lower portion of the specimen under these circumstances. This appears to be supported by a specimen that failed in that region.

In all the tests, it was observed that the initial period of UPP increase was associated with a significant initial period of change in measured parameters, followed by plateauing to a limiting value, or at least a relatively slowly changing value. It is possible that this characteristic was due to the effect of hysteresis in bulk wool's elastic properties resulting from the process of initially charging the chamber with wool (where wool was forced into the chamber up to the initial density of $300 \mathrm{~kg} \mathrm{~m}^{-3}$ prior to the main compression). A further effect was that, at pressures above $1 \mathrm{MPa}$, wool was compressed sufficiently to truly exhibit properties of the bulk material, whereas at lower densities fiber-bending may predominate.

\section{CONCLUSION}

In conclusion, a novel experimental press was developed for investigations into the high-density compression of bulk wool. The press was designed to give useful results of relevance to the wool dumping industry. The press size was a critical factor in the design, due to considerations of practicality of tests, repeatability of results, cost, and time to perform experiments. Results obtained from the experimental press illustrate the interesting nonlinear characteristics of wool and may be of interest to the wool dumping industry in regard to the design and operation of presses.

\section{ACKNOWLEDGEMENTS}

The authors wish to gratefully acknowledge the contributions of Mr. Alastair McKenzie for initiating this work, Mr. John Wyatt and Mr. Grant Rivett for their technical assistance, and the Wool Research and Development Corporation for funding this research. 


\section{REFERENCES}

Burrow, R. P. 1983. Unpublished technical memoranda. Victoria, Australia: University of Melbourne, Department of Civil and Agricultural Engineering.

David, H. G., and J. G. Downs. 1968. A note on the behaviour of greasy wool under biaxial compression. J. Institution of Eng. Australia 40(4): 79-82.

Gale, T. J., and G. A. Moore. 1990. The effect of staple length when pressing wool to high density. In Proc. Institution of Engineers Australia Conf. on Agricultural Engineering, 1990, 352-355. Canberra, Australia: The Institution of Engineers, Australia.

Guruparan, N. I., N. Haritos, and G. A. Moore. 1990. Application of finite element analysis to the compression of fibrous materials. In Proc. 12th Australasian Conference on Mechanics of Structures and Materials, 237-242. Brisbane, Australia: Queensland Institute of Technology.

Lhuede, E. P. 1968. Development of a wool dump for processing vacuum pressed bales. J. Institution of Eng. Australia 40(4): 73-77.

Moore, G. A., T. J. Gale, and R. P. Burrow. 1988. The effect of scale when pressing wool to high density. In Proc. Institution of Engineers Australia Conf. on Agricultural Engineering, 1988, 407-410. Canberra, Australia: The Institution of Engineers, Australia.
Thompson, B., and K. J. Whitely. 1985. The measurement of resistance to compression: Part I. The effect of sample preparation. J. Text. Inst. 76(2): 64-73.

Tyndale-Biscoe, J. P., T. J. Gale, and G. A. Moore. 1990. The development of a triaxial press for fibrous agricultural materials. In Proc. Institution of Engineers Australia Conf. on Agricultural Engineering, 1990, 315-318. Canberra, Australia: The Institution of Engineers, Australia.

Van Wyk, C. M. 1946. Note on the compressibility of wool. J. Text. Inst. 37: T285-292.

Volchenock, V. I., and E. G. Doktorov. 1972. Experimental investigation of the baling of unwashed wool. Tech. of Textile Industry, USSR 1: 16-18.

Walls, G. W. 1988a. Biaxial compression of hot greasy wool to high densities and its subsequent storage. Text. Res. J. 58(3): 137-141.

Walls, G. W. 1988b. Minimum volume pressing of greasy wool. Text. Res. J. 58(1): 43-50.

WRONZ. 1972. Compression of Wool Bales: Forces on the Surface of the Bale Chamber. N. F. Roberts, M. J. Hammersley, A. Barker, W. Van Pelt, and J. Carson. Christchurch, New Zealand: Wool Research Organisation of New Zealand. 